\title{
Article
}

\section{A Performance Measurement Tool (PMT) to Control Maintenance-Associated Infections}

Njuangang, Stanley, Liyanage, Champika Lasanthi and Akintoye, Akintola

Available at http://clok.uclan.ac.uk/13952/

Njuangang, Stanley ORCID: 0000-0002-9325-3749, Liyanage, Champika Lasanthi ORCID: 0000-0001-6687-3611 and Akintoye, Akintola ORCID: 00000002-0611-5824 (2016) A Performance Measurement Tool (PMT) to Control Maintenance-Associated Infections. Facilities, 34 (13/14). pp. 766-787. ISSN 0263-2772

It is advisable to refer to the publisher's version if you intend to cite from the work. http://dx.doi.org/10.1108/F-12-2014-0107

For more information about UCLan's research in this area go to http://www.uclan.ac.uk/researchgroups/ and search for <name of research Group>.

For information about Research generally at UCLan please go to http://www.uclan.ac.uk/research/

All outputs in CLoK are protected by Intellectual Property Rights law, including Copyright law. Copyright, IPR and Moral Rights for the works on this site are retained by the individual authors and/or other copyright owners. Terms and conditions for use of this material are defined in the policies page.

\section{CLoK}

Central Lancashire online Knowledge www.clok.uclan.ac.uk

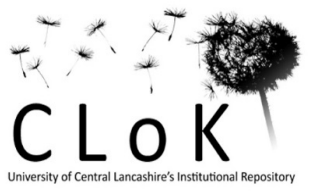




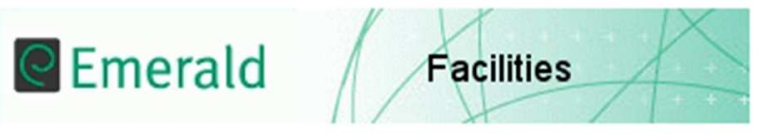

\section{Performance Measurement Tool (PMT) to Control Maintenance-Associated Infections}

\begin{tabular}{|r|l|}
\hline Journal: & Facilities \\
\hline Manuscript ID & f-12-2014-0107.R3 \\
\hline Manuscript Type: & Original Article \\
\hline Keywords: & BSC, CSFs, HAIs, Infection Control, Maintenance, Performance measures \\
\hline \multicolumn{2}{|c}{} \\
\hline
\end{tabular}

\section{SCHOLARONE ${ }^{\text {Tx }}$ \\ Manuscripts}<smiles>C1=COC1</smiles> 
Table 1: Categorisation of the CSFs and Performance Measures According to the BSC Perspectives

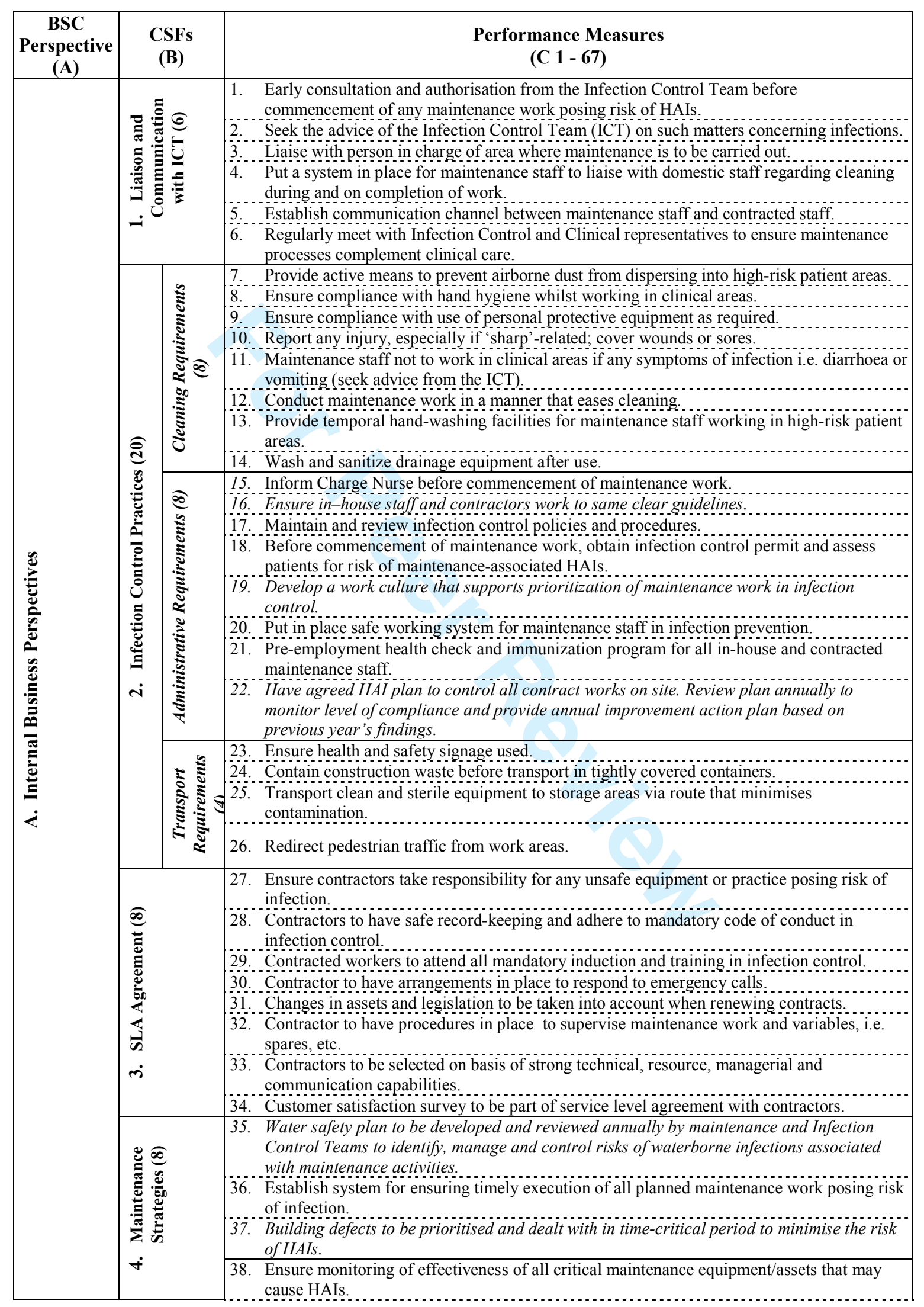


Table 2: Establishing the Level of Importance of CSFs and Performance Measures

\begin{tabular}{|c|c|c|c|c|c|c|c|c|c|c|c|}
\hline \multirow{4}{*}{$\begin{array}{l}\text { (A) } \\
\text { BSC } \\
\text { Perspective }\end{array}$} & \multirow{4}{*}{$\begin{array}{l}\text { (B) } \\
\text { CSFs }\end{array}$} & \multirow{4}{*}{$\begin{array}{l}\text { (C) } \\
\text { Performance } \\
\text { Measures }\end{array}$} & \multirow{4}{*}{$\begin{array}{l}\text { (D) } \\
\text { Mean } \\
\text { Score }\end{array}$} & \multirow{4}{*}{$\begin{array}{l}\text { (E) } \\
\text { Rank }\end{array}$} & \multicolumn{5}{|c|}{ Mean scales and weight (W) } & \multicolumn{2}{|c|}{ Weighted Mean } \\
\hline & & & & & $\begin{array}{l}\text { Zone } \\
\text { I. }\end{array}$ & $\begin{array}{l}\text { Zone } \\
\text { II. }\end{array}$ & $\begin{array}{l}\text { Zone } \\
\text { III. }\end{array}$ & $\begin{array}{l}\text { Zone } \\
\text { IV. }\end{array}$ & $\begin{array}{l}\text { Zone } \\
\text { V. }\end{array}$ & \multirow{3}{*}{$\begin{array}{l}\text { Total (E) } \\
\Sigma(C \times W) / C\end{array}$} & \multirow{3}{*}{$\begin{array}{l}\text { Level of } \\
\text { Importance } \\
\text { of CSF }\end{array}$} \\
\hline & & & & & $\begin{array}{l}\leq 3.82 \\
\text { to } \geq 4\end{array}$ & $\begin{array}{l}\leq 3.64 \quad \text { to } \\
>3.82\end{array}$ & $\begin{array}{ll}\leq 3.46 \quad \text { to } \\
>3.64\end{array}$ & $\begin{array}{l}\leq 3.28 \\
\text { to }>3.46\end{array}$ & $<3.28$ & & \\
\hline & & & & & $W=4$ & $\mathrm{~W}=3$ & $W=2$ & $W=1$ & $W=0$ & & \\
\hline \multirow{33}{*}{$\begin{array}{l}\text { Internal } \\
\text { Business } \\
\text { Processes }\end{array}$} & \multirow{6}{*}{$\begin{array}{l}\text { 1. Liaison and } \\
\text { Communication } \\
\text { with the Infection } \\
\text { Control Team (ICT) }\end{array}$} & $\mathrm{C}-1$ & 4.0000 & 1 & \multirow{6}{*}{$2(4)=8$} & \multirow{6}{*}{$1(3)=3$} & \multirow{6}{*}{$1(2)=2$} & \multirow{6}{*}{$2(1)=2$} & \multirow{6}{*}{ - } & \multirow{6}{*}{$15 / 6$} & \multirow{6}{*}{2.5} \\
\hline & & $\mathrm{C}-2$ & 3.9333 & 3 & & & & & & & \\
\hline & & $\mathrm{C}-3$ & 3.7333 & 13 & & & & & & & \\
\hline & & $\mathrm{C}-4$ & 3.5333 & 26 & & & & & & & \\
\hline & & $\mathrm{C}-5$ & 3.3333 & 46 & & & & & & & \\
\hline & & $\mathrm{C}-6$ & 3.3333 & 46 & & & & & & & \\
\hline & $\begin{array}{ll}\text { 2. } & \begin{array}{l}\text { Infection Control } \\
\text { Practices }\end{array} \\
\end{array}$ & $\mathbf{N}=\mathbf{2 0}$ & & & $4(5)=20$ & $3(3)=9$ & $5(2)=10$ & $4(1)=4$ & $4(0)=0$ & $43 / 20$ & 2.15 \\
\hline & \multirow{8}{*}{$\begin{array}{ll}- & \text { Cleaning } \\
& \text { Requirements }\end{array}$} & $C-7$ & 4.0000 & 1 & \multirow{8}{*}{$3(4)=12$} & \multirow{8}{*}{$2(3)=6$} & & \multirow{8}{*}{$1(1)=1$} & \multirow{8}{*}{$2(0)=0$} & \multirow{8}{*}{$19 / 8$} & \multirow{8}{*}{2.375} \\
\hline & & $\mathrm{C}-8$ & 3.8667 & 7 & & & & & & & \\
\hline & & C -9 & 3.8667 & 7 & & & & & & & \\
\hline & & $C-10$ & 3.6667 & 17 & & & & & & & \\
\hline & & $C-11$ & 3.6429 & 20 & & & & & & & \\
\hline & & $\mathrm{C}-12$ & 3.4000 & 38 & & & & & & & \\
\hline & & $\mathrm{C}-13$ & 3.2000 & 56 & & & & & & & \\
\hline & & C-14 & 3.2000 & 56 & & & & & & & \\
\hline & - Administrative & $C-15$ & 3.9333 & 3 & & & & & & & \\
\hline & Requirements & C-16 & 3.8000 & 11 & & & & & & & \\
\hline & & $C-17$ & 3.6000 & 21 & & & & & & & \\
\hline & & $\mathbf{C}-18$ & 3.6000 & 21 & $l(4)=4$ & $l(3)=3$ & $4(2)=8$ & $1(1)=1$ & {$[(0)=0$} & $16 / 8$ & 2 \\
\hline & & C-19 & 3.5833 & 25 & $I(4)=4$ & $I(3)=3$ & $4(2)=8$ & $I(1)=1$ & $I(0)=0$ & $10 / 8$ & 2 \\
\hline & & C -20 & 3.5333 & 26 & & & & & & & \\
\hline & & $\mathrm{C}-21$ & 3.4286 & 36 & & & & & & & \\
\hline & & $C-22$ & 3.0000 & 61 & & & & & & & \\
\hline & - Transport & $\mathrm{C}-23$ & 3.4667 & 31 & & & & & & & \\
\hline & Requirements & $C-24$ & 3.4000 & 38 & & & $1(2)=2$ & $2(1)=2$ & $1(0)=0$ & 44 & 1 \\
\hline & & $C-25$ & 3.4000 & 38 & & - & $1(2)-2$ & $2(1)-2$ & $1(0)-0$ & $4 / 4$ & $T$ \\
\hline & & $C-26$ & 3.2000 & 56 & & & & & & & \\
\hline & 3. $\quad$ SLA Agreement & $\mathrm{C}-27$ & 3.7692 & 12 & & & & & & & \\
\hline & & $\mathrm{C}-28$ & 3.7333 & 13 & & & & & & & \\
\hline & & $\mathrm{C}-29$ & 3.7143 & 15 & 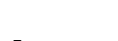 & $3(3)=0$ & $2(0)=4$ & $2(1)=?$ & $1(0)=0$ & $15 / 8$ & 1875 \\
\hline & & $\mathrm{C}-\mathbf{3 0}$ & 3.5333 & 28 & - & $3(3)=-9$ & $2(2)=4$ & $2(1)=2$ & $1(0)=0$ & $10 / 8$ & $1.8 / 5$ \\
\hline & & $\mathrm{C}-\mathbf{3 1}$ & 3.4667 & 31 & & & & & & & \\
\hline & & $\mathrm{C}-32$ & 3.3333 & 46 & & & & & & & \\
\hline
\end{tabular}




\begin{tabular}{|c|c|c|c|c|c|c|c|c|c|c|c|}
\hline & & $\begin{array}{l}\mathrm{C}-33 \\
\mathrm{C}-34\end{array}$ & \begin{tabular}{|l|}
3.2857 \\
2.9333 \\
\end{tabular} & $\begin{array}{l}52 \\
65\end{array}$ & & & & & & & \\
\hline & 4. $\quad$ Maintenance & $\mathrm{C}-35$ & 3.9167 & 6 & \multirow{8}{*}{$1(4)=4$} & \multirow{8}{*}{$1(3)=3$} & \multirow{8}{*}{$1(2)=2$} & \multirow{8}{*}{$2(1)=2$} & \multirow{8}{*}{$3(0)=0$} & \multirow{8}{*}{$11 / 8$} & \multirow{8}{*}{1.37} \\
\hline & Strategies & $\mathrm{C}-36$ & 3.7143 & 15 & & & & & & & \\
\hline & & $\mathrm{C}-37$ & 3.6000 & 21 & & & & & & & \\
\hline & & $\mathrm{C}-38$ & 3.4000 & 38 & & & & & & & \\
\hline & & $\mathrm{C}-39$ & 3.4000 & 38 & & & & & & & \\
\hline & & $\mathrm{C}-40$ & 3.3333 & 46 & & & & & & & \\
\hline & & $\mathrm{C}-41$ & 3.2667 & 54 & & & & & & & \\
\hline & & $\mathrm{C}-42$ & 2.9993 & 64 & & & & & & & \\
\hline & \multirow{4}{*}{ 5. Risk Assessment } & $\mathrm{C}-43$ & 3.6667 & 17 & & \multirow{4}{*}{$1(3)=3$} & \multirow{4}{*}{$1(2)=2$} & \multirow{4}{*}{$1(1)=1$} & \multirow{4}{*}{$1(0)=0$} & \multirow{4}{*}{$6 / 4$} & \multirow{4}{*}{1.5} \\
\hline & & $\mathrm{C}-44$ & 3.4667 & 31 & & & & & & & \\
\hline & & $\mathrm{C}-45$ & 3.4000 & 38 & & & & & & & \\
\hline & & $\mathrm{C}-46$ & 3.2000 & 56 & & & & & & & \\
\hline \multirow{7}{*}{ Financial } & 6. Maintenance & $\mathrm{C}-47$ & 3.9333 & 3 & \multirow{7}{*}{$3(4)=12$} & \multirow{7}{*}{ - } & \multirow{7}{*}{ - } & \multirow{7}{*}{$2(1)=2$} & \multirow{7}{*}{$2(0)=0$} & \multirow{7}{*}{$14 / 7$} & \multirow{7}{*}{2} \\
\hline & Resource & $\mathrm{C}-48$ & $\begin{array}{ll}3.8667 \\
\end{array}$ & 7 & & & & & & & \\
\hline & Availability & $\mathrm{C}-49$ & \begin{tabular}{|l|l|}
3.8667 \\
\end{tabular} & 7 & & & & & & & \\
\hline & & C-50 & 3.4545 & 35 & & & & & & & \\
\hline & & $\mathrm{C}-51$ & 3.3333 & 46 & & & & & & & \\
\hline & & $C-52$ & \begin{tabular}{|l|l|}
3.2500 \\
\end{tabular} & 55 & & & & & & & \\
\hline & & $\mathrm{C}-53$ & 2.6000 & 67 & & & & & & & \\
\hline \multirow{9}{*}{$\begin{array}{l}\text { Innovation } \\
\text { and } \\
\text { Learning }\end{array}$} & $\begin{array}{ll}\text { 7. } & \begin{array}{l}\text { Staff Training } \\
\text { and Development }\end{array}\end{array}$ & $N=8$ & & & & $1(3)=3$ & $2(2)=4$ & $4(1)=4$ & $1(0)=0$ & $11 / 8$ & 1.4 \\
\hline & \multirow{4}{*}{$-\quad$ Training } & $\mathrm{C}-54$ & 3.6000 & 21 & & \multirow{4}{*}{ - } & & & & & \\
\hline & & $C-55$ & 3.5000 & 29 & & & & & & $6 / 4$ & \\
\hline & & $\mathrm{C}-56$ & 3.4000 & 46 & & & $2(2)=4$ & $2(1)=2$ & $5^{-}$ & $0 / 4$ & 1.0 \\
\hline & & $C-57$ & 3.3333 & 38 & & & & & & & \\
\hline & - Development & $C-58$ & 3.6667 & 17 & & & & & & & \\
\hline & & $\mathrm{C}-59$ & 3,4286 & 36 & & $1(3)=3$ & - & $2(1)=2$ & $1(0)=0$ & $5 / 4$ & 1.3 \\
\hline & & $C-60$ & 3.2857 & 52 & & (ग) & - & $2(1)-2$ & & & \\
\hline & & $\mathrm{C}-61$ & 3.0000 & 61 & & & & & & & \\
\hline Customer & & $\mathrm{C}-62$ & 3.5000 & 29 & & & & & & & \\
\hline Satisfaction & & $\mathrm{C}-63$ & \begin{tabular}{|l|l|}
3.4667 \\
\end{tabular} & 31 & & & & & & & \\
\hline & 8. Customer & $\mathrm{C}-64$ & 3.4000 & 38 & & & & & & & \\
\hline & Satisfaction & $\mathrm{C}-65$ & 3.1333 & 60 & & - & $2(2)=4$ & $1(1)=1$ & $3(0)=0$ & $5 / 6$ & 0.8 \\
\hline & & C-66 & 3.0000 & 61 & & & & & & & \\
\hline & & C- 67 & $\begin{array}{ll}2.8667 \\
\end{array}$ & 62 & & & & & & & \\
\hline & Total & 67 & & & $10(14.9)$ & $9(13.4 \%)$ & 11(16.4\%) & $23(34 \%)$ & $14(20.8)$ & - & \\
\hline
\end{tabular}


Table 3: Performance Measurement Tool (PMT) in HM in IC (An Exemplar)

\begin{tabular}{|c|c|c|c|c|c|c|c|c|c|c|c|c|}
\hline \multirow{2}{*}{$\begin{array}{l}\text { Mean } \\
\text { Zones }\end{array}$} & \multirow{2}{*}{ Selected Performance Measures (P) } & \multicolumn{5}{|c|}{$\begin{array}{l}\text { Performance } \\
\text { Level Rating (L) }\end{array}$} & \multirow{2}{*}{$\begin{array}{l}\text { Weighting } \\
\text { (W) }\end{array}$} & \multirow{2}{*}{$\begin{array}{l}\text { Weighted } \\
\text { Score WS = } \\
(\mathbf{L} \times \mathbf{W})\end{array}$} & \multirow{2}{*}{$\begin{array}{l}\text { Performance Score 1- } \\
\text { for each Performance } \\
\text { Measure } \\
\frac{(\mathrm{L})}{(5)} \times 100 \\
\end{array}$} & \multirow{2}{*}{$\begin{array}{l}\text { Performance Score 2- } \\
\text { for each Individual } \\
\text { Mean Zone }\end{array}$} & \multirow[t]{2}{*}{$\begin{array}{l}\text { Performance Score } 3- \\
\text { Considering all Mean Zones }\end{array}$} & \multirow[t]{2}{*}{$\begin{array}{l}\text { Overall Performance of the } \\
\text { HMU in HAI }\end{array}$} \\
\hline & & 1 & 2 & 3 & 4 & 5 & & & & & & \\
\hline \multirow{3}{*}{ 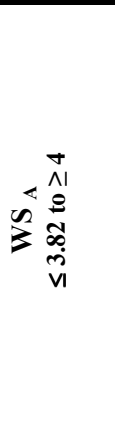 } & $\begin{array}{l}\text { I. Implement early consultation and } \\
\text { authorization from the Infection Control } \\
\text { Team before commencement of any } \\
\text { maintenance work posing risk of HAIs. }\end{array}$ & (e. & & & 4 & & 4 & $16\left(\mathrm{WS}_{1}\right)$ & $80 \%$ & \multirow[t]{3}{*}{$\frac{\left(\mathbf{W S}_{1}+\mathbf{W S}_{2}+\mathbf{W S}_{3}\right)}{\mathbf{N}\left(\mathbf{P}_{A}\right) \times\left(\mathbf{L}^{*} \mathbf{W}\right)} \times 100$} & \multirow[t]{3}{*}{$\frac{\Sigma\left(\mathrm{WS}_{\mathrm{A}}\right)}{\Sigma\left(\mathrm{WS}_{\mathrm{A}}+\mathrm{WS}_{\mathrm{B}}+\mathrm{WS}_{\mathrm{C}}+\mathrm{WS}_{\mathrm{D}}\right)} \times 100$} & \multirow{10}{*}{$\begin{array}{l}\Sigma\left(\mathrm{WS}_{\mathrm{A}}+\mathrm{WS}_{\mathrm{B}}+\mathrm{WS}_{\mathrm{C}}+\mathrm{WS}_{\mathrm{D}}\right) \\
30.77+16.15+15.38+3.08 \\
=\mathbf{6 5 . 3 8 \%}\end{array}$} \\
\hline & 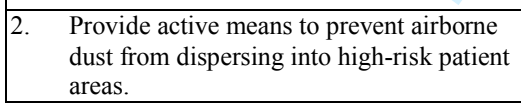 & ce & & 3 & 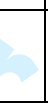 & & 4 & $12\left(\mathrm{WS}_{2}\right)$ & $60 \%$ & & & \\
\hline & $\begin{array}{l}\text { W. Water safety plan to be developed (and } \\
\text { reviewed annually) by maintenance and } \\
\text { Infection Control Teams to identify, } \\
\text { manage and control risks of waterborne } \\
\text { infections associated with maintenance } \\
\text { activities. }\end{array}$ & & & 3 & & & 4 & $12\left(\mathrm{WS}_{3}\right)$ & $60 \%$ & & & \\
\hline \multirow{2}{*}{ 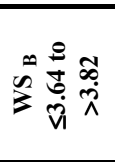 } & $\begin{array}{ll}4 . & \begin{array}{l}\text { Ensure in-house staff and contractors } \\
\text { work to same clear guidelines. }\end{array} \\
\end{array}$ & & & & 4 & & 3 & $12\left(\mathrm{WS}_{4}\right)$ & $80 \%$ & \multirow[t]{2}{*}{$\frac{(12+9)}{2(15)} \times 100$} & \multirow[b]{2}{*}{$\begin{array}{l}\frac{(12+9)}{130} \times 100 \\
=\mathbf{1 6 . 1 5 \%}\end{array}$} & \\
\hline & $\begin{array}{l}\text { 5. } \begin{array}{l}\text { Contracted workers to attend all } \\
\text { mandatory induction and training in } \\
\text { infection control. }\end{array} \\
\end{array}$ & & & 3 & & & 3 & $9\left(\mathrm{WS}_{5}\right)$ & $60 \%$ & & & \\
\hline \multirow{3}{*}{ 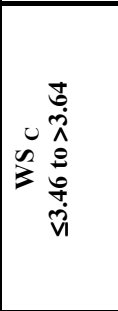 } & \begin{tabular}{|l}
6. \\
$\begin{array}{l}\text { Put a system in place for maintenance staff } \\
\text { to liaise with domestic staff regarding } \\
\text { cleaning during and on completion of } \\
\text { work. }\end{array}$ \\
\end{tabular} & 1 & & & & & 2 & $2\left(\mathrm{WS}_{6}\right)$ & $20 \%$ & \multirow[t]{3}{*}{$\frac{(2+10+8)}{3(10)} \times 100$} & \multirow[t]{3}{*}{$\frac{(2+10+8)}{130} \times 100$} & \\
\hline & $\begin{array}{|ll|}7 . & \begin{array}{l}\text { System to be implemented to review and } \\
\text { analyse complaints about maintenance } \\
\text { services and to recommend improvement. }\end{array} \\
\end{array}$ & & & & & 5 & 2 & $10\left(\mathrm{WS}_{7}\right)$ & $100 \%$ & & & \\
\hline & $\begin{array}{ll}\text { 8. } & \begin{array}{l}\text { Skilled and competent staff to be } \\
\text { employed to ensure safe and efficient } \\
\text { maintenance operations. }\end{array}\end{array}$ & & & & 4 & & 2 & $8\left(\mathrm{WS}_{8}\right)$ & $80 \%$ & & & \\
\hline \multirow{2}{*}{ 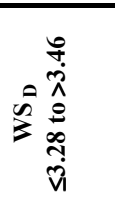 } & \begin{tabular}{|l} 
9. \\
$\begin{array}{l}\text { Regularly meet with Infection Control and } \\
\text { Clinical representatives to ensure } \\
\text { maintenance processes complement } \\
\text { clinical care. }\end{array}$ \\
\end{tabular} & 1 & & & & & 1 & $1\left(\mathrm{WS}_{9}\right)$ & $20 \%$ & \multirow[t]{2}{*}{$\frac{(1+3) \times 100}{2(5)}$} & \multirow[t]{2}{*}{$\frac{(1+3)}{130} \times 100$} & \\
\hline & \begin{tabular}{|l}
10. \\
$\begin{array}{l}\text { Site induction on infection control to be } \\
\text { conducted within a few weeks of } \\
\text { employment. }\end{array}$ \\
\end{tabular} & & & 3 & & & 1 & $3\left(\mathrm{WS}_{10}\right)$ & $30 \%$ & & & \\
\hline \multicolumn{8}{|c|}{ Weighted Score for all Mean Zones } & 85 & & & & \\
\hline
\end{tabular}




\section{Introduction}

The term Hospital-acquired infections (HAI) usually means infections that were neither present nor incubating when a patient, visitor or hospital staff member enters the hospital (National Audit Office (NAO), 2004). HAIs are a major problem to healthcare institutions throughout the world. According to estimates by the World Health Organisation, out of every one hundred patient admitted to hospital at any one time, seven in the developed and ten in the developing countries acquire at least one type of HAI (WHO, 2002). The European Centre for Disease Control and Prevention estimates that about 3.2 million patients in European acute care hospitals acquire HAIs every year (ECDC, 2013).

Before the introduction of mandatory surveillance, about $9 \%$ of inpatients in the UK acquired an HAI during their stay in hospital (Parliamentary Office of Science and Technology, 2005). However, since the introduction of mandatory surveillance in 2001, there has been a steady fall in the rate of Meticilline-resistant Staphylococcus aureus (MRSA) and Clostridium difficile (C. difficile) in England (Health Protection Agency (HPA), 2012). According to HPA (2009), MRSA bloodstream infections in England fell from 6,383 in $2006 / 07$ to 2,933 in $2008 / 09$ (a $54 \%$ reduction). Equally, the rate of C. Difficile fell from 55,499 in $2007 / 08$ to 36,097 in $2008 / 09$ (a 35\% reduction). By reducing the rate of MRSA and $C$. Difficile, the NHS has been able cut costs in areas such as drug therapy, hospital readmissions and ward closures.

Apart from those infections i.e. MRSA and C. Difficile, which are under mandatory surveillance, there is no evidence suggesting that rates of HAIs are falling. The BBC (2014) estimates that about 300,000 inpatients acquire an HAI each year - that is, one in every 16 patient being treated by the NHS. Figures released by ECDC (2013) show that the rate of $C$. difficile in England is higher than in the Netherlands, France, Spain and Italy. The deputy chief executive of the National Institute for Health and Clinical Excellence noted, "It is 
unacceptable that infection rates are still so high in within the NHS” (BBC, 2014). These figures could even be higher, as estimates of HAI in England do not take into full account HAI acquired after a patient has been discharged from hospital. According to the NAO (2000), about 50-70\% of surgical wound infections occur post-discharge. Apart from prolong a stay in hospital, HAIs may also worsen the patient's underlying condition, inflict pain and bring unnecessary misery to family members and friends.

In addition to the human cost of HAI is the financial cost, which has raised the concern of health authorities and the public. The total cost of HAI to the NHS is about $£ 986.36$ million annually, with the larger part of the money $£ 930.62$ million being incurred by the in-patient services (NAO, 2000). The remaining $£ 55.74$ million is incurred post discharge by GPs, outpatient consultants and district nursing services. The cost of treating a patient who acquires one or more HAI whilst receiving treatment at the hospital is 2.8 times greater than for a patient without an infection. This additional cost is incurred directly by the NHS on such issues as increased length of hospital stay, additional antibiotic therapy, repeated surgery, food, testing (laboratory and radiography) etc. On average, a patient infected with HAI cost the NHS an additional $£ 2,917$ to treat. Costs generally range from $£ 1,222$ for urinary tract infections to $£ 6,209$ for blood infections (NAO, 2000). In 2007-8, the NHS spent at least $£ 20$ million and $£ 75$ million treating patients with MRSA and C. difficile infections respectively (NAO, 2009). Litigation cost is also set to grow following successful legal claims for compensation after acquiring HAI.

Despite the huge cost of HAIs, through better infection control practices, the NHS could reduce the incidence of HAI by up to $15-30 \%$ (NAO, 2004). Any reduction in the cost of HAI in the NHS could free up additional cash, which could then be used in the provision of alternative healthcare related priorities. According to the National Institute for Health and Clinical Excellence, every 5\% reduction in the rate of MRSA and C. Difficile could result in a cost saving of about $£ 4.9$ million annually to the NHS (NICE, 2011). 
All this suggests that healthcare officials need to adopt a holistic approach that focuses on tackling the root causes of hospital-acquired infections. Usually these causes take one of two forms, i.e. clinical or non-clinical. Presently, it appears that insufficient attention is paid to the non-clinical causes of HAIs in hospitals. The non-clinical causes of HAIs are normally associated with poor performance on the part of healthcare facilities management services in infection control (IC). Such services include for example cleaning (to avoid contamination of equipment and the built environment), catering (to avoid food contamination), building maintenance (to avoid cross-infection), and practices of healthcare facilities management workers (to avoid contact transmission) (WHO, 2002). The two areas that seem to attract the most attention from healthcare authorities are cleaning and catering. This is because cleaning is often seen by the public and trade unions (i.e. Unison) as the cause of infections, i.e. MRSA and C. Difficile. The same is true of catering, which is often blamed for food poisoning outbreaks such as food-borne salmonellosis at the Stanley Royd Hospital.

Apart from cleaning and catering, however, healthcare facilities management services are treated as though they have no connection with IC. Yet epidemiological evidence gathered in this research also implicates healthcare maintenance in the incidence of HAIs in hospitals. In the next section, the significance of healthcare maintenance in IC is examined in depth. For reasons of space, this research focuses exclusively on healthcare maintenance, and particularly on performance measurement in this area. To present this, the paper is divided into two main sections. In the first section, the rationale for the selection of healthcare maintenance is provided; in the second section, the focus is on the development of a performance measurement tool (PMT) in healthcare maintenance in IC.

\subsection{Maintenance services in the control of HAIs}

Without an efficient and well-coordinated maintenance function, it is unlikely that buildings will function properly. Maintenance can prevent disruption of core business activities that 
may have cost implications and undesirable outcomes (e.g. customer dissatisfaction, noncompliance with legal requirements, health and safety problems, increased energy consumption and damage to the environment, etc. (Lam, 2007). The Yeovil District Hospital NHS (2009, p.3) defines healthcare maintenance as the "combination of all technical and administrative actions, including supervision actions, intended to keep an item in, or restore it to, a state in which it can perform a required function. Given due consideration to viability and economic financial responsibilities".

The nature of the business of hospitals requires that the healing indoor environment "considers infection control safety for patients and staff as an added factor for a safe environment of care" (Streifel, 2005, p.1). Evidence gathered from the literature shows a causal link between maintenance works carried out in and around hospitals and HAI. In hospitals, maintenance work has been implicated in the spread of conidia through the airborne route (Hoffman et al., 1999). According to Tabbara and Jabarti (1998), old hospitals (termed 'sick' buildings) are more likely to harbour spores of fungi, including Aspergillus. Although fungi (Aspergillum species) are naturally occurring, ubiquitous and a natural part of the biological ecosystem (Burrill 2008), they pose a significant risk to patients whose immunity has been compromised because of age, underlying illness or medical or surgical treatment (Joseph 2006). Invasive aspergillosis affects $\leq 14$ per cent of lung transplant recipients and $\leq 28$ per cent of patients who have undergone allogeneic hematopoietic stem cell transplantation (Wald et al., 1997). In Canada alone, about 50\% of negative patient outcomes (including several deaths) have been caused by Aspergillus fumigatus (Health Canada, 2001, cited in Burrill, 2008). Such figures have led the Centres for Disease Control and Prevention (2005, as cited in Burrill, 2008: p. 56) to state that "HAIs may be associated with dust exposure during building renovation [maintenance] or construction".

Despite all this, it appears the issue of maintenance-associated infections (infections caused by maintenance activities in hospitals) has failed to attract the full attention of 
healthcare officials. As a result, the healthcare maintenance department and NHS Trust maybe pursuing different objectives in IC. Lee and Scott (2008) blame this on maintenance staff for relying too much on their technical experience and skills and not connecting with core business objectives. Others have also attributed this to confusing and piecemeal core business objectives that pay little attention to building maintenance. According to Hicks (2004), some healthcare establishments have not even realised the benefits of having written missions, visions, goals and objectives for their maintenance departments. Those written statements that are in place have focus mainly on cost (Lee and Scott, 2008). Such a culture can create a dysfunctional maintenance department that has no business orientation.

Because top managers generally lack an understanding of the science of maintenance, they appear to rely on the old tenet 'if it isn't broke, don't fix it' (Chalifoux and Baird, 1999). As a result, they are often reluctant to allocate a sufficient budget to allow the maintenance department carry out comprehensive maintenance strategies. Whilst slashing the budget allocated to strategies such as preventive maintenance may offer short-term cost savings, it may increase the probability of failures. In the words of Thun (2004, cited in Bivona and Montemaggiore, 2005), this creates a vicious cycle: “'Repairs eat up Prevention' results in a situation with many unexpected machine breakdowns and an overloaded maintenance department".

Following criticisms of the performance of healthcare maintenance services in IC, some NHS hospitals have started formulating policies to minimise the risk of maintenanceassociated HAIs. However, there appears to be wide variation in the number of IC issues addressed in healthcare maintenance policies across the NHS. In addition, little is known about whether these policies are effectively implemented and realised by healthcare maintenance departments. According to Healthcare Facilities Scotland (2007), there is a problem with the effective dissemination and implementation of existing policies and guidelines in a logical and accessible form to all involved in the control of HAI in the NHS. 
Instead of focusing on the core business issues of the NHS (i.e., infection control), most healthcare maintenance managers spend considerable time and energy focusing on reactive measures to reduce costs

The above discussion clearly highlights the consequences of a lack of performance measurement in healthcare maintenance in IC. Generally, healthcare facilities management services like maintenance have a poor understanding of performance measurement and its application to IC (Liyanage and Egbu, 2005). Even where attempts have been made to measure performance in relation to infection control, they use only a limited number of indicators and measures. The purpose of this paper is therefore to fill this gap by developing a tool that measures performance adequately in healthcare maintenance in IC. As outlined in the next section, this was achieved using a three-step process.

\section{The process adopted for developing a performance measurement tool (PMT)}

It is clear from the above discussion that improving the performance of the healthcare maintenance department in IC will help the NHS reduce its current rate of HAIs. As stated earlier, a Performance Measurement Tool was developed using a three-step process:

Step 1. Identification of the critical success factors (CSFs) and performance measures in healthcare maintenance in IC. Here, a brief discussion is provided about the methodology, i.e. the literature reviews, grounded theory and the balanced scorecard (BSC) used to identify the CSFs and performance measures. The BSC is described in section 2.1 .

Step 2. Ranking the CSFs according to their importance in IC. This was achieved on the basis of the results of a three-round Delphi study (refer to section 2.2).

Step 3. Developing a PMT in healthcare maintenance to measure performance in IC. Here weightings were assigned to the performance measures identified through the 
Delphi study, and formulae established for calculating the performance of the healthcare maintenance department in IC at various levels.

\subsection{Step 1 - Identifying the CSFs and Performance Measures in IC}

Today's business environment is much more dynamic than it used to be many years ago. Besides stiff competition, organisations also face the challenges of meeting the needs of their stakeholders. Healthcare maintenance departments in the NHS cannot ignore such challenges. The widespread mechanisation and automation of companies has reduced the number of production personnel, and increased the capital employed in production equipment. Consequently, the number of maintenance staff has grown alongside the proportion of total operating costs spent on maintenance. The technological needs arising from a better understanding of the causes of diseases, together with an ever-increasing number of susceptible patients, have revolutionised the process of healthcare maintenance. Today's healthcare maintenance has to grapple with complex electrical, heating, plumbing, air conditioning, mechanical and medical equipment and devices in order to meet the needs of the NHS.

An important step towards meeting some of these challenges is measuring the performance of the healthcare maintenance department in IC. In this paper, it is argued that this should be achieved through the development of a PMT. According to Tsang (1998, p. 87), "considering maintenance a purely tactical matter is myopic". The first step in the development of the PMT is the identification of the CSFs and performance measures in healthcare maintenance in IC. CSFs are “...key areas of performance that are essential for the organisation to accomplish its mission [goals, objectives, or projects]" (Caralli, 2004, p. 2). Performance measures on the other hand are “... specific standards which allow the calibration of performance for each critical success factor, goal, or objective" (Bullen and Rockart, 1981, p. 8). CSFs and performance measures can provide healthcare maintenance 
managers with valuable information to drive performance in healthcare maintenance in IC effectively.

An in-depth review of relevant research materials was conducted to identify the CSFs and performance measures in healthcare maintenance in IC. Strict criteria were adopted in the selection process. The research materials needed to contain rich information concerning the control and prevention of maintenance-associated HAIs in hospitals. In total, the literature review resulted in the selection of 27 key IC documents: seven government documents, 10 healthcare maintenance policies and 10 clinical peer-reviewed journals.

Grounded theory analyses of the 27 selected documents resulted in the identification of 56 performance measures in healthcare maintenance in IC. In contrast to the usual treatment of this topic elsewhere, these performance measures were categorised under eight CSFs. According to Lavy et al. (2010), little attempt has been made in facilities management to group performance measures according to criteria that allow interrelationships to be properly understood and analysed. As shown in Table 1, the eight CSFs in healthcare maintenance in IC are Liaison and Communication with the Infection Control Team, Infection Control Practices, Maintenance Strategies, Risk Assessment, Maintenance Resource Availability, Staff Education and Customer Satisfaction. For the purpose of clarity, some of the CSFs were sub-divided. For example, the 'Infection Control Practices' was divided into Cleaning, Administrative and Transport Requirements (see Table 1).

Traditionally, most organisations restrict performance measurement in maintenance to the tracking of direct costs or their surrogates such as the headcount of tradesmen (Tsang, 1998). In order to drive overall performance across the healthcare maintenance department, managers must also focus on non-financial measures. Therefore, the 56 performance measures and eight CSFs were further categorised into the four perspectives of the (BSC): Financial, Internal Business Processes, Innovation and Learning, and Customers. The BSC is one of the most widely recognised performance measurement systems (Neely et al., 2000), 
and is the most widely applied in facilities management (Toni et al., 2007). The four perspectives of the BSC have been commended by many for driving overall performance in organisations. Therefore, this research draws on the strengths of the BSC perspectives in the development of a performance measurement tool that considers the financial and nonfinancial measures in healthcare maintenance in IC.

\section{Insert Table 1}

\subsection{Step 2: Ranking the CSFs according to their importance in IC}

In the second stage of the research process, the different levels of importance of the CSFs and performance measures were established, as they were categorised into different mean zones. In establishing the levels of importance of the CSFs and performance measures, a three-round Delphi study was applied. The Delphi study has been accepted for publication in the International Journal of Health care Quality Assurance under the title 'Key performance measures to control maintenance-associated HAIs', Volume, 28; Issue, 7. The Delphi participants were purposively selected across Acute NHS Trusts in England. For people to be considered as Delphi participants, they needed to have extensive healthcare maintenance and IC experience and knowledge, and to have occupied healthcare maintenance manager or IC team member positions (i.e., as IC doctors, nurses or microbiologists) in an acute NHS trust for at least five years. In addition, it was a requirement that participation in the Delphi study was not to be delegated to someone else.

The CSFs and performance measures identified in the first process (literature review) were used to design the Round 1 Delphi instrument. In the first round of the Delphi exercise, the participants were presented with the CSFs and performance measures identified in the literature and given the task of identifying new ones. The first round Delphi exercise results were then used to modify the second round Delphi instrument. Delphi participants provided comments and suggestions that led to re-wording and in some instances re-structuring 
sections. The Round 1 Delphi results were analysed manually. In total, 11 new performance measures were identified in the first round of the Delphi exercise. These are italicised in Table I.

In the second round, participants were asked to rate 67 performance measures. The rating was based on a four-point Likert scale, where scales 1 and 2 ('very important' and 'important') represented the positive category, and scales 3 and 4 ('unimportant' and 'very unimportant') the negative category. The results of the Round 2 Delphi exercise were inputted into the SPSS (version 21) statistical software, and analysed through descriptive statistics. The decision to retain a performance measure in any Delphi round required that both healthcare maintenance managers and IC members agreed. Therefore, for a performance measure to be retained in any round, the participants had to achieve a group mean score of 3.28 or above. Any performance measure with a group mean less than 3.28 was re-submitted to the Delphi participants for re-rating.

Between the second and third rounds of the Delphi exercise, healthcare maintenance managers and IC members identified 53 important performance measures in healthcare maintenance in IC. These are shown in Table 2 (columns D and E). The codes $(\mathrm{C}-1$ to $\mathrm{C}-$ 67) that are used for the performance measures in Table 2 (column C) correspond to the list of performance measures in Table 1. Although most studies of this nature traditionally end here, this research study did not. At this stage of the research, it appears as though all the performance measures with a high level of consensus have the same level of importance in IC. According to Lavy et al. (2010), this problem is caused by the fact that there are too many performance measures (or indicators) in facilities management. For example, in a study conducted by Hinks and McNay (2005), 172 performance measures were identified. In another example, the Delphi participants in a study on organisational readiness for clinical information technology/system innovation identified up to 316 performance measures (Snyder-Halpern, 2001). According to Tangen (2004), it costs organisations money and time 
to analyse too many performance measures. Too many performance measures may result in information overload. As the organisation grapples with many performance measures, it becomes difficult for them to prioritize.

As time is money, it is necessary for organisations to collect data only on meaningful CSFs and performance measures, i.e. those that offer important insights. One factor that may limit the benefits of such an exercise in facilities is the lack of a meaningful categorisation of CSFs and performance measures (Lavy et al., 2010). In a few studies where some sort of categorisation has been applied, the level of importance of the CSFs under which the performance measures are categorised has not been established. This adds to the difficulty of selecting appropriate performance measures to drive performance in the organisation. This study therefore attempts to establish the level of importance of the CSFs in infection control. For this purpose, three steps were proposed:

1. Categorisation of the performance measures into different mean zones: Since the Delphi exercises were conducted on a four-point Likert scale, the mean zones were established by dividing the difference between the maximum and minimum level of consensuses by four $(4-3.28 / 4)$. This produces four mean zones (I, II, III and IV) with intervals of approximately 0.18 . These were then linked to the CSFs, which are categorised according to the four perspectives of the BSC. If the mean score of the performance measure is $X$, the mean zone it belongs to is identified using the following scale $\leq 3.82$ to $\geq 4$ (Mean Zone I), $\leq 3.64$ to $>3.82$ (Mean Zone 2), $\leq 3.46$ to $>3.64$ (Mean Zone 3), and $\leq 3.28$ to $>3.46$ Mean Zone 4). All those performance measures with a mean score of less than 3.28 were categorised in a fifth mean zone and given a weight of zero. As shown in Table 2, there were $10(14.9 \%)$ performance measures under mean zone 1 , and $14(20.8 \%)$ performance measures under mean zone V. The majority of important performance measures $(54.8 \%)$ were categorised under mean zones III and IV. 
2. Assign weights to the mean zones: The mean zones were given weighted scores of between 4 and 1, where 4 and 1 represent the highest and lowest mean scores respectively. In a number studies in fields such as education (Ohio Department of Education, 2007) and climate change (Emerson et al., 2012) methodologies that are different from this one have been used to weight items. The weights have not been assigned according to mean zones. In education, for example, different performance levels ('untested students', 'below limited', 'basic', 'proficient', 'accelerated' and 'advanced') are assigned different weights. Performance is calculated by simply multiplying the number of students in a performance level by the weight and dividing the results by overall possible score. In this research, this has been achieved differently (refer to section 2.3).

3. Establish the levels of importance of the CSFs: The level of importance of the CSFs in IC was determined through a research technique called the weighted mean. The weighted mean is different from the mean in that some data points contribute more than others do. For every CSF, the number of performance measures categorised under the different mean zones were multiplied by the weighted score. These were then added, and divided by the total number of performance measures for that particular CSF to give its level of importance. The results of the CSFs according to their levels of importance in IC are presented in Table 2. So far, the most important CSFs in healthcare maintenance in IC are 'Liaison and Communication between the Healthcare Maintenance Department and IC Team', 'Infection Control Practices' (Cleaning and Administrative Requirements)', and 'Maintenance Resource Availability'. On the other hand, the least important CSFs are 'Customer Satisfaction', 'Transport Requirements', 'Staff Training', and 'Staff Development'.

The ranking of the performance measures 1 - 67 (column E, Table 2) indicates that some performance measures are more important than others are. For example, even though 'Liaison and Communication with the Infection Control Team' is the most important CSF, 
the performance measures $(\mathrm{C}-1$ to $\mathrm{C}-6)$ have varying levels of important in healthcare maintenance in IC. The six measures achieved rankings of 1, 3, 13, 26, 46 and 46, and the range between the first and sixth performance measure is 45 . Variations also exist in the level of importance of the performance measures under the eight different CSFs. Therefore, there is a need to develop a performance measurement tool (PMT) that enables healthcare maintenance managers to select the most important performance measures from the eight CSFs, in order to drive performance in IC. The PMT that has been developed in this research attempts to meet some of these needs.

\section{INSERT TABLE 2}

\subsection{The Development of a PMT in healthcare maintenance in IC}

As shown in Table 3, a performance measurement tool (PMT) was devised in this research to enable healthcare maintenance managers to quantify performance in IC. The PMT should enable healthcare maintenance managers to establish the level of performance against individual performance measures, as well as against a group of performance measures in a mean zone. Where there is more than one mean zone, the PMT allows healthcare maintenance managers to measure and compare the performance of all mean zones at the same time. Finally, through the application of the PMT, healthcare maintenance managers will be able state the level of performance of the healthcare maintenance department in IC. The PMT has to be used in conjunction with the results and categorisation of the performance measures achieved through the Delphi exercise (Table 2).

It is advised that the healthcare maintenance managers work closely with members of the infection control team for the selection of pertinent performance measures that will help drive the performance of the healthcare maintenance department in IC. Performance measures should be selected according to their level of importance in IC from all the four perspectives of the BSC. They should also be categorised according to the four mean zones of 
the PMT using the mean score results presented in Table 2. The fifth mean zone (see Table 2) contains unimportant performance measures. As shown in Table 3, the four mean zones of the PMT are coded $\mathrm{WS}_{\mathrm{A}}, \mathrm{WS}_{\mathrm{B}}, \mathrm{WS}_{\mathrm{C}}$ and $\mathrm{WS}_{\mathrm{D}}$. These mean zones are also assigned weights of 4,3,2,1 respectively. For every selected performance measure, the healthcare maintenance manager at the end of the measurement exercise should state the result that is achieved on a scale of $1-5$. In doing so, they must take into account the interpretation given to the rating scale. The rating scale (L) that is proposed in this research ranges from very poor to excellent (1 - 'very poor', 2 - 'poor', 3 - 'average', 4 - 'good', 5 - 'excellent'). Conversely, the scale for interpreting the results of the PMT ranges from poor to excellent $(\geq 1 \%$ to $<25 \%$ - 'very poor', $\geq 25 \%$ to $<50 \%$ - 'average', $\geq 50 \%$ - $<75 \%$ - 'good', $\geq 75 \%$ - $\leq 100 \%$ - 'excellent').

Since the performance measures have varying levels of importance in IC, it is important to consider the weights. Therefore, the weighted score (WS) for each performance measure is calculated by multiplying the achieved level of performance (L) against the assigned weight (W). However, the performance on individual performance measures can be calculated simply by dividing the assigned level of performance (L) by 5 - the maximum level of performance for a performance measure. Since the results are presented in percentages, the result is then multiplied by a hundred. Information gathered about individual mean zones allows the healthcare maintenance manager to identify whether the objectives and targets of the healthcare maintenance department in IC are being met. The formula used to score individual performance measures in the PMT is given as:

$\underline{(\mathrm{L})} \times 100$

Where:

L - Level of performance 


\section{INSERT TABLE 3}

The PMT can also be applied to calculate the level of performance of performance measures in a mean zone, e.g. $\mathrm{WS}_{\mathrm{A}}$. The calculations presented in the column entitled 'Performance Score 2' (Table 3) take into account only the performance measures in one mean zone. Performance in a mean zone is calculated by first adding the weighted scores in the mean zone. The result is then divided by the total number of performance measures multiplied by the maximum weighted score for that mean zone and then multiplied by 100 . As shown in Table 3, the performance of the mean zone $\mathrm{WS}_{\mathrm{A}}$ is $66.6 \%$. According to the classification developed in this research, the level of performance of the healthcare maintenance department is considered 'good'. This however suggests scope for further improvement in the performance of the healthcare maintenance in IC. The results obtained for individual performance measures in a mean zone could be used to gauge areas for further improvement. The formula for calculating performance in a mean zone is given as:

$\left.\underline{\mathrm{WS}}_{1}+\mathrm{WS}_{2}+\mathrm{WS}_{3}\right) \times 100$

$\mathrm{N}\left(\mathrm{P}_{\mathrm{A}}\right) \times(\mathrm{L} \times \mathrm{W})$

Where:

$\mathrm{WS}_{1}, \mathrm{WS}_{2}, \mathrm{WS}_{3}-$ Weighted score for individual performance measures

$\mathrm{N}\left(\mathrm{P}_{\mathrm{A}}\right)-$ Number of performance measures in a mean zone

$(\mathrm{L} \times \mathrm{W})$ - Maximum weighted score for a performance measure

Where there is more than one mean zone, the performance of a mean zone is calculated by taking into account all the performance measures of the other mean zones. This allows healthcare maintenance managers to compare performance across different mean zones. It 
also indicates where resources and effort should be directed. As shown in Table 3, when the mean zones are aggregated, the level of performance of the mean zones falls. This is because the weights of the different performance measures are factored into the calculations. The PMT also allows the healthcare maintenance manager to estimate the overall performance of the healthcare maintenance department in IC. To calculate 'performance score 3' (in Table 3 ), the first step is to add the weighted scores of the performance measures in any of the mean zones (i.e. $\left(\mathrm{WS}_{1}+\mathrm{WS}_{2}+\mathrm{WS}_{3}\right)$ ). This is then divided by the total number of performance measures in the mean zones, multiplied by their respective maximum weighted scores. The final score is again multiplied by 100 . In the example provided, the performance of mean zones $\mathrm{WS}_{\mathrm{A}}, \mathrm{WS}_{\mathrm{B}}, \mathrm{WS}_{\mathrm{C}}$ and $\mathrm{WS}_{\mathrm{D}}$ are $30.77 \%, 16.15 \%, 15.38 \%$ and $3.08 \%$ respectively. The formula for calculating performance in more than one mean zone is:

$$
\frac{\underline{\Sigma\left(\mathrm{WS}_{\mathrm{A}}\right)}}{\Sigma\left(\mathrm{WS}_{\mathrm{A}}+\mathrm{WS}_{\mathrm{B}}+\mathrm{WS}_{\mathrm{C}}+\mathrm{WS}_{\mathrm{D}}\right)} \times 100
$$

Where:

$\Sigma-$ Sum

$\mathrm{WS}_{\mathrm{A}}-$ Weighted score of mean zone ' $\mathrm{A}$ '

$\mathrm{WS}_{\mathrm{B}}-$ Weighted score of mean zone ' $\mathrm{B}$ '

$\mathrm{WS}_{\mathrm{C}}-$ Weighted score of mean zone 'C'

$\mathrm{WS}_{\mathrm{D}}$ - Weighted score of mean zone ' $\mathrm{D}$ '

To improve on the result of the mean zones, managers have to improve in the performance of individual performance measures in the mean zone. Assuming that the three performance measures in $\mathrm{WS}_{\mathrm{A}}$ achieved $100 \%$, the performance of $\mathrm{WS}_{\mathrm{A}}$ will be $46.1 \%$. Similarly, those for $\mathrm{WS}_{\mathrm{B}}, \mathrm{WS}_{\mathrm{C}}$ and $\mathrm{WS}_{\mathrm{D}}$ will be $23.1 \%, 23.07 \%$ and $7.7 \%$ respectively (totalling $100 \%$ ). The above figures clearly show that emphasis is on the most critical performance measures. Only 
three out of the ten performance measures in the PMT are categorised in the mean zone $\mathrm{WS}_{\mathrm{A}}$. Notwithstanding, they account for $46.1 \%$ of the overall performance score. The overall performance score for $\mathrm{WS}_{\mathrm{B}}$ and $\mathrm{WS}_{\mathrm{C}}$ are similar, though fewer performance measures were selected for $\mathrm{WS}_{\mathrm{B}}$.

The overall performance of the healthcare maintenance department in IC is calculated by simply adding the percentage scores of the four mean zones (performance score 3 in Table 3). In the example provided, the performance of the healthcare maintenance is $65.38 \%$. This can also be calculated by dividing the total weighted scores $\left(\mathrm{WS}_{1}-\mathrm{WS} 10\right)$ by the total number of performance measures in the mean zones multiplied by the respective maximum weighted scores. This is multiplied by 100. In the example provided in Table 3, the total achieved weighed scores for all four mean zones are 85. Conversely, the maximum weighted score for all the four mean zones are $\mathrm{WS}_{\mathrm{A}}(3 \times 20)+\mathrm{WS}_{\mathrm{B}}(2 \times 15)+\mathrm{WS}_{\mathrm{C}}(3 \times 10)+\mathrm{WS}_{\mathrm{D}}(2$ $\times 5)=130$.

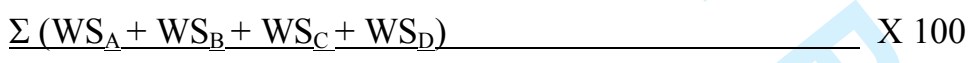

$\Sigma\left[\mathrm{N}\left(\mathrm{P}_{\mathrm{A}}\right) \times 20\right]+\left[\mathrm{N}\left(\mathrm{P}_{\mathrm{B}}\right) \times 15\right)+\left[\mathrm{N}\left(\mathrm{P}_{\mathrm{C}}\right) \times 10\right]+\left[\mathrm{N}\left(\mathrm{P}_{\mathrm{D}}\right) \times 5\right]$

$85 / 130 \times 100=65.38 \%$

Where:

$\Sigma-$ Sum

$\mathrm{WS}_{\mathrm{A}}, \mathrm{WS}_{\mathrm{B}}, \mathrm{WS}_{\mathrm{C}}, \mathrm{WS}_{\mathrm{D}}-$ Weighted score of the mean zones

$\mathrm{N}\left(\mathrm{P}_{\mathrm{A}}\right)$ - Number of performance measures in mean zone ' $\mathrm{A}$ '

$\mathrm{N}\left(\mathrm{P}_{\mathrm{B}}\right)$ - Number of performance measures in mean zone ' $\mathrm{B}$ '

$\mathrm{N}\left(\mathrm{P}_{\mathrm{C}}\right)$ - Number of performance measures in mean zone ' $\mathrm{C}$ '

$N\left(P_{D}\right)$ - Number of performance measures in mean zone ' $D$ ' 
Relying on the scale applied in the PMT, the performance of the healthcare maintenance department in IC in this example is interpreted as good. Yet poor performance is clearly indicated against some of the performance measures. The results of 'performance score 1' indicate those performance measures with poor performance in IC. This information can be used by the healthcare maintenance manager to focus attention on the most crucial performance measures in IC (i.e. those with a weighted score of 4). Conversely, the information can also be used to replace those performance measures that have achieved a $100 \%$ score in IC. The formula provided above can also be used to benchmark the performance of healthcare maintenance departments in IC across the NHS.

\section{Conclusion}

This research has demonstrated how the results achieved from a Delphi study can be further analysed to direct resources, time and effort to the most critical CSFs and performance measures in healthcare maintenance in IC. The performance measures identified in the Delphi study were categorised into five mean zones. By assigning weights to the mean zones, it was possible to distinguish between the eight CSFs according to levels of importance in IC. Through the application of a statistical method called the weighted mean, 'Liaison and Communication with the IC Team' emerged as the most important CSF in healthcare maintenance in IC. The second most important CSF identified was 'Infection Control Practices'. Of the three sub-groups under 'Infection Control Practices', 'Cleaning Requirements' attained the best result in IC. Although 'Customer Satisfaction' and 'Maintenance Strategies' ranked bottom, they also contained performance measures that were ranked highly in IC.

The five mean zones provide clarity about the level of importance of the performance measures in healthcare maintenance in IC. Since the CSFs and performance measures are also selected from the four areas of the BSC, performance is driven from all the critical areas of 
the healthcare maintenance department in IC. This of course is one of the key strengths of the PMT: the selection of performance measures from eight CSFs that have been categorised into the four perspectives of the BSC: internal business processes, financial, innovation, learning and customer satisfaction perspectives.

Through the application of the PMT, healthcare maintenance managers are able to measure performance in three levels. In each of these performance levels, performance measurement is driven by the weightings of the performance measures. Healthcare maintenance manager are thus able to verify whether poor results are coming from the most important or least important performance measures. Since the PMT allows healthcare maintenance managers to gather information about individual performance measures, resources and effort can easily be prioritised. The PMT that has been developed here could be used to benchmark healthcare maintenance services across NHS hospitals. Obviously, issues related to the healthcare maintenance strategy, mission, goals, objectives, targets, etc. will have to be addressed by individual healthcare maintenance departments. Having identified the CSFs and performance measures through expert opinion, the next challenge will be to test and validate the PMT across healthcare maintenance departments in the NHS.

\section{References}

British Broadcasting Corporation. 2014, "Hospital Infection Rates Must Come Down, Says Watchdog", BBC, available at: http://www.bbc.co.uk/news/health-27046990 (accessed January 20 2015).

Bivona, E. and Montemaggiore, G. (2005), "Evaluating Fleet and Maintenance Management Strategies through System Dynamics Model in a City Bus Company”, available at: http://www.systemdynamics.org/conferences/2005/proceed/papers/MONTE431.pdf (accesses 22 September 2014). 
Bullen, C. V. and Rockart, J. F. (1981), “A primer on critical success factors”, no. 1220-81, Centre for Information Systems Research, Massachusetts Institute of Technology (MIT). Burrill, G. (2008), "Healthcare Construction under way", available at: http://www.touchbriefings.com/pdf/3202/burrill.pdf (accessed 27 September 2012).

Caralli, R. (2004), "The Critical Success Factor Method: Establishing a Foundation for Enterprise Security Management', Carnegie Mellon Software Engineering Institute, Pittsburgh.

Centres for Disease Control and Prevention. (2003), "CDC guidelines for infection control”, available at: https://www.premierinc.com/safety/topics/guidelines/cde_guidelines.jsp (accessed 20 July 2012).

Chalifoux, A. and Baird, J. (1999), "Reliability Centered Maintenance (RCM) Guide: Operating a More Effective Maintenance Program, US Army Corps of Engineers, Illinois.

Emerson, J., Esty, D., Hsu, A., Levy, M., Sherbinin, A., Mara, V. and Jaiteh, M. 2012, “2012 Environmental Performance Index and Pilot Trend Environmental Performance Index", Yale University.

European Centre for Disease Prevention and Control. (2013), "Point Prevalence Survey of Healthcare-Associated Infections and Antimicrobial use in European Acute Care Hospitals 2011-2012”, Surveillance Report no. 2011-2012, ECDPC, Stockholm.

Hicks, M. L. (2004), “Hospital Maintenance Strategic Plan at the University of Michigan Hospital and Health Centers", Business Briefing, available at: http://www.touchbriefings.com/pdf/747/hosp041_hicks.pdf (Accessed 5 October 2011).

Hinks, J. and McNay, P. (1999), "the Creation of a Management-by-variance Tool for Facilities Management Performance Assessment”, Facilities, Vol. 17 No. 1/2, pp. 31-53.

Hoffman, P. N., Bennett, A. M. and Scott, G. M. (1999), “Controlling Airborne Infections”, Journal of Hospital Infection, Vol. 43, pp. 203-210. 
Joseph, A. (2006), "The Impact of Environment on Infections in Healthcare Facilities" Centre for Health Design, California.

Kidd, F., Buttner, C. and Kressel, A. B. (2007), "Construction: A Model Program for Infection Control Compliance", American Journal of Infection Control, Vol. 35 No. 5, pp. $347-350$.

Lam, K. (2007), "Design for Maintenance from the Viewpoint of Sustainable Hospital Buildings”, available at: http://mail.airah.org.au/downloads/2007-12-02.pdf (accessed 5 February 2011).

Lavy, S., Garcia, J. A. and Dixit, M. K. (2010), "Establishment of KPIs for Facility Performance Measurement: Review of Literature”, Facilities, Vol. 28 No. 9/10, pp. $440-464$.

Lee, H., Hackman and Scott, D. (2008), "Development of a Conceptual Framework for the Study of Building Maintenance Operation Processes in the Context of Facility Management”, Surveying and Built Environment, Vol. 19 No. 19, pp. 81-101.

Liyanage, C. and Egbu, C. (2005), “Controlling Healthcare Associated Infections (HAI) and the Role of Facilities Management in Achieving "Quality" in Healthcare: a ThreeDimensional View”, Facilities, Vol. 23 No. 5/6, pp. 194-215.

National Audit Office, 2009. "Reducing healthcare associated infections in hospitals in England". NAO, London.

National Audit Office, 2004. “Improving patient care by reducing the risk of hospital acquired infection", NAO, London.

National Audit Office. (2000), “The Management and Control of Hospital Acquired Infection in Acute NHS Trusts in England HC”, NAO, London.

National Institute for Health and Clinical Excellence. (2011), "Prevention and Control of Healthcare-Associated Infections”, Costing report No. 36, NICE, Manchester. 
Neely, A., Mills, J., Platts, K., Richards, H., Gregory, M., Bourne, M. and Kennerley, M. (2000), "Performance Measurement System Design: Developing and Testing a Processbased Approach", International Journal of Operations \& Production Management, Vol. 20 No. 10, pp.1119-1145.

Ohio Department of Education. (2007), 'Performance Index', Educational Management Information System (EMIS), Ohio.

Ohsaki, Y., Koyano, S., Tachibana, M., Shibukawa, K., Kuroki, M., Yoshida, I. and Ito, Y. (2007), "Undetected Bacillus Pseudo-Outbreak after Renovation Work in a Teaching Hospital”. Journal of Infection, Vol. 54 No. 6, pp. 617-622.

Riley, D., Freihaut, J., Bahnfleth, W. and Karapatyan, Z. (2004), "Indoor Air Quality Management and Infection Control in Healthcare Facilities", available at www.engr.psu.edu/iec/publications/papers/indoor_air_quality.pdf (accessed 27 July 2012).

Snyder-Halpern, R. (2001), "Indicators of Organizational Readiness for Clinical Information Technology/Systems Innovation: a Delphi Study”, International Journal of Medical Informatics, Vol. 63 No. 3, pp. 179-204.

Streifel, A. (2005), "Infection Control Factors in Hospital Building Maintenance and Operations", Hospital Engineering and Facilities.

Tabbara, K. F., \& Jabarti, A. A. (1998), "Hospital Construction-Associated Outbreak of Ocular Aspergillosis after Cataract Surgery”, Ophthalmology, Vol. 105 No. 3, pp. 522526.

Tangen, S. (2004), "Performance Measurement: from Philosophy to Practice" International Journal of Productivity and Performance Management, Vol. 53 No. 8, pp. 726-737.

Toni, A. F. D., Fornasier, A., Montagner, M. and Nonino, F. (2007), “A Performance Measurement System for Facility Management: The Case Study of a Medical Service 
Authority", International Journal of Productivity and Performance Management, Vol. 56 No. 5/6, pp. $417-435$.

Tsang, A. H. C. (1998), “A Strategic Approach to Managing Maintenance Performance”, Journal of Quality in Maintenance Engineering, Vol. 4 No. 2, pp. 87-94.

Wald, A., Leisenring, W., Burik, J. and Bowden, R. A. 1997, "Epidemiology of Aspergillus Infections in a Large Cohort of Patients Undergoing Bone Marrow Transplantation”, Journal of Infectious Diseases, Vol. 175 No. 6, pp. 1459-66.

World Health Organisation. (2002), “Guidelines on Prevention and Control of Hospital Associated Infections", WHO, New Delhi.

Yeovil District Hospital NHS. (2009). Estates Maintenance Policy (including Planned Preventative Maintenance), NHS, Yeovil. 